\title{
The influence of organic matter content and media compaction on the dispersal of entomopathogenic nematodes with different foraging strategies
}

\author{
APOSTOLOS KAPRANAS*†, ABIGAIL M. D. MAHER and CHRISTINE T. GRIFFIN \\ Department of Biology, Maynooth University, Maynooth, Co. Kildare, Ireland
}

(Received 6 April 2017; revised 6 Fune 2017; accepted 18 Fune 2017; first published online 14 August 2017)

SUMMARY

In laboratory experiments, we investigated how media with varying ratio of peat:sand and two levels of compaction influence dispersal success of entomopathogenic nematode (EPN) species with different foraging strategies: Steinernema carpocapsae (ambusher), Heterorhabditis downesi (cruiser) and Steinernema feltiae (intermediate). Success was measured by the numbers of nematodes moving through a $4 \mathrm{~cm}$ column and invading a wax moth larva. We found that both compaction and increasing peat content generally decreased EPN infective juvenile (IJ) success for all three species. Of the three species, $H$. downesi was the least affected by peat content, and $S$. carpocapsae was the most adversely influenced by compaction. In addition, sex ratios of the invading IJs of the two Steinernema species were differentially influenced by peat content, and in the case of $S$. feltiae, sex ratio was also affected by compaction. This indicates that dispersal of male and female IJs is differentially affected by soil parameters and that this differentiation is species-specific. In conclusion, our study shows that organic matter: sand ratio and soil compaction have a marked influence on EPN foraging behaviour with implications for harnessing them as biological pest control agents.

Key words: entomopathogenic nematodes, soil organic matter, peat, soil compaction, foraging behaviour, dispersal, infection, sex ratio.

\section{INTRODUCTION}

Soil is a complex biomaterial (O’Donnell et al. 2007) that serves as a reservoir of a wide range of insect pathogens and parasites, such as viruses, bacteria, protozoa, fungi and nematodes (Klingen and Haukeland, 2006). Some of these parasites have soil-transmitted infective stages that need to find hosts, and thus, soil properties modulate biotic interactions between these parasites and their hosts. Soil properties affect patterns of invertebrate locomotion, foraging behaviour and resource exploitation (Kaczmarek, 1978; MacMillan et al. 2009; Cornelius and Osbrink, 2010; Kaspi et al. 2010; Mathieu et al. 2010). Moreover, soil modification, such as compaction (the increase in bulk density or decrease in porosity of soil due to externally or internally applied loads), can have an important influence on soil biota (Aritajat et al. 1977; Bouwman and Arts, 2000; Eaton et al. 2004; Beylich et al. 2010).

Entomopathogenic nematodes (EPN) are one of the most important insect pathogens in soil recognized for their ecosystem services; they have generally broad host range and are commercially

\footnotetext{
* Corresponding author: Department of Biology, Maynooth University, Maynooth, Co. Kildare, Ireland. E-mail: apostolos.kapranas@unine.ch

$\dagger$ Present address: Institute of Biology, University of Neuchâtel, Neuchâtel, 2000, Switzerland.
}

produced and marketed around the world as bioinsecticides (Lacey et al. 2015). Transmission is achieved by means of a specialized juvenile stage, the infective juvenile (IJ). Typically EPN IJs are applied at the soil surface (e.g. by drenching) with the aim of killing pests feeding in the rhizosphere, such as white grubs (Coleoptera: Scarabaeidae) and weevils (Coleoptera: Curculionidae) (Lacey and Georgis, 2012). An important feature of EPN biology that has implication for their use in biological control is their foraging strategy, that is described as lying on a continuum from 'ambushing', sit and wait species to 'cruising', more actively moving species (Grewal et al. 1994; Campbell et al. 2003; Lewis et al. 2006). EPN that have been categorized as cruising foragers, such as Heterorhabditis and some Steinernema species, are allegedly better suited to control soil-dwelling insect pests, whereas nematodes that are categorized as ambush foragers, such as Steinernema carpocapsae (Weiser), are traditionally recommended for use against soil surface active pests (Campbell and Gaugler, 1993; Kaya and Gaugler, 1993). However, more recently, it has become clear that $S$. carpocapsae may also be effective against distant, immobile hosts (Dillon et al. 2006; Martinez de Altube et al. 2008).

A large number of studies have investigated how soil properties, including texture, moisture content and chemistry, affect EPN dispersal and hostfinding behaviour and consequently their success

Parasitology (2017), 144, 1956-1963. C Cambridge University Press 2017. This is an Open Access article, distributed under the terms of the CreativeCommons Attribution licence (http://creativecommons.org/licenses/by/4.0/), which permits unrestricted re-use, distribution, and reproduction in any medium, provided the original work is properly cited. 
in providing control of soil-dwelling insect pests (Stuart et al. 2015). Nematodes move in films of moisture over soil particles and pass through the narrow channels between them. What determines the ease with which they move through a soil is largely a function of pore space in relation to the size of the animals themselves (Wallace, 1968). Pore space is a function both of the size of particles (soil texture) and their packing (compaction). Most studies on soil texture have focussed on the mineral components of standard agricultural soils, investigating how the relative proportions of sand, clay and silt influence EPN locomotion and foraging efficiency; these have provided strong evidence that in heavy clay soils, IJ movement is hampered and EPN are not as effective, whereas increasing the proportion of sand improves their success (Georgis and Poinar, 1983; Kung et al. 1990; Portillo-Aguilar et al. 1999; Koppenhöfer and Fuzy, 2006; Kaspi et al. 2010; El-Borai et al. 2012). Bulk density (compaction) interacts with soil texture to influence pore size and hence the locomotion of soil inhabitants (Hunt et al. 2001), and has been shown to affect dispersal and infection by EPN in a species-specific manner (Portillo-Aguilar et al. 1999; Gruner et al. 2007), though this factor has received rather little attention. Similarly, little attention has been paid to the effect that the organic matter content of soils may have on EPN efficacy. The limited number of studies that have been done have compared soil types that also differ in properties other than organic matter content, e.g. comparing highly organic soil or potting mix against mineral soils with low organic matter (Choo and Kaya, 1991; Koppenhöfer and Fuzy, 2006), or correlations across field soils varying in organic matter content (Kaspi et al. 2010). These studies provide evidence that organic matter can have an important influence on EPN behaviour and efficacy, with differences between EPN species as to which conditions are best. A unique (to our knowledge) study investigated the effect of amending organic media with sand. Addition of up to $50 \%$ sand by volume improved the foraging success of Steinernema riobrave (Cabanillas, Poinar and Raulston), but not of Heterorhabditis bacteriophora (Poinar) (Nielsen and Lewis, 2011). This type of study is of relevance in designing the ideal potting mix for EPN, which have been shown to be effective in a range of organic soil-less media used in nurseries (Oetting and Latimer, 1991; Ansari and Butt, 2011; Nielsen and Lewis, 2011), but also in addressing more fundamental questions regarding foraging type and niche specialization.

Recently, it has been suggested that the ability of nematodes with ambush foraging strategies, such as $S$. carpocapsae, to move efficiently in organic media, such as peat, and parasitize soil pests there, indicates that they are habitat specialists rather than having different foraging strategies (Kruitbos et al. 2010; Wilson et al. 2012). It is claimed that this holds true because in numerous field studies, $S$. carpocapsae appears to be effective against immobile pests either within soils, some of them characterized by high content of organic matter, such as peat (Dillon et al. 2006, 2007; Torr et al. 2005; Martinez de Altube et al. 2008; Dembilio et al. 2010; Williams et al. 2013; Kapranas et al. 2017a, b), or within other media, such as wood and leaf litter (Lacey and Unruh, 1998). In addition, it has been suggested that in steinernematid nematodes, and depending on the species, either males of females have superior capabilities in colonizing hosts (Grewal et al. 1993; Bohan and Hominick, 1997). In this study, we use laboratory assays to address how EPN species with different foraging strategies move downward in media of varying organic matter (peat) and compaction. Moreover, we explore whether any of these species can be characterized as better adapted to disperse in organic matter, as shown for S. carpocapsae, examining thus evidence for the habitat specialization hypothesis (Kruitbos et al. 2010; Wilson et al. 2012). We also hypothesize that, if indeed there are differences between female and males in their ability to colonize hosts, then we predict that there will be sex ratio shifts in the infecting IJs as the conditions for their dispersal become more or less favourable.

\section{MATERIALS AND METHODS}

\section{Nematodes}

The nematodes used in this experiment were: Heterorhabditis downesi Stock, Griffin \& Burnell K122, Steinernema feltiae (Filipjev) 4CFMO and S. carpocapsae. All nematodes were cultured at $20^{\circ} \mathrm{C}$ in late instar larvae of the greater wax moth, Galleria mellonella (L.) (obtained from The Mealworm Company, Sheffield, UK), using standard protocols (Kaya and Stock, 1997). Harvested IJs were washed three times by sedimentation in tap water and stored at $9{ }^{\circ} \mathrm{C}$ until use.

\section{Assay}

A single $G$. mellonella larva was enclosed in a wire cage and placed in the bottom of a $60 \mathrm{~cm}^{3}$ plastic pot $(4 \mathrm{~cm} \times 4.4 \mathrm{~cm}, \mathrm{H} \times \mathrm{D}$, with snap on lid; Wains of Tunbridge Wells, UK) and peat/sand mix was added to each pot. Peat (Shamrock Irish Moss Peat, Bord na Mona Horticulture, Newbridge, Ireland) was passed through a $1 \mathrm{~cm}$ sieve, and visible pieces of plant material were removed by hand. Sand (B \& Q Play Pit sand, Kingfisher plc, London, $\mathrm{UK}$ ) was passed through a $1.4 \mathrm{~mm}$ sieve. Moisture content of sand was adjusted to $8 \%(\mathrm{w} / \mathrm{w})$. The moisture content of the peat was on average $57 \%$ (ranging 
from 54 to $60 \cdot 7 \%$ ). Five media were prepared, with the following ratios of peat:sand $(\mathrm{v} / \mathrm{v}): 100: 0,75: 25$, 50:50, 25:75 and 0:100. For non-compacted treatments, pots were filled to the top with peat:sand mixture, which was levelled off. For compacted treatments, soil was added to the pot, compacted by tapping the pot three times on a flat surface and applying light pressure with the thumbs. More mixture was then added, compacted by applying light pressure with the thumbs and levelled off at the top. A small depression was made in the centre of each pot and $100 \mathrm{IJs}$ in $100 \mu \mathrm{L}$ of tap water were added. The filled weight of pots was recorded (Table 1). Pots were lidded and incubated at $20^{\circ} \mathrm{C}$ for $24 \mathrm{~h}$. Insects were removed from the soil and incubated at $20^{\circ} \mathrm{C}$ for a further 3 days to allow them to die and the IJs inside to develop to adult. Any insects that showed the characteristic colour and appearance of nematode infection were dissected and the number of first-generation adult nematodes was counted. For steinernematids, the sex of the nematodes was recorded. Both live and dead adults were counted, as steinernamatid males might appear dead due to fatal fights, but can be observed easily upon dissection of the Galleria larvae (O'Callaghan et al. 2014; Zenner et al. 2014; Kapranas et al. 2016). In a small number of insects displaying the characteristics of nematode infection, no nematodes were found and these were recorded as a single nematode invasion. Any insects with signs of death - other than those caused by EPN (distinguished by characteristic colour and consistency) were excluded from the dataset.

There were four or five rounds of the experiment for each nematode species. Each round of the experiment consisted of five or eight replicate pots for each of 10 treatments (five levels of peat:sand mixture and two levels of compaction) for one nematode species. Each round was conducted with a different culture batch of nematodes. The total number of replicate pots per treatment was 23,26 or 28 for $S$. carpocapsae, $H$. downesi and $S$. feltiae, respectively. Controls (no nematodes) were not included as in our experience natural mortality of wax moths is negligible in these assay conditions.

\section{Statistical analysis}

Generalized linear modelling was used to explore the influence of EPN species, sand content and compaction on mortality rates of Galleria larvae and also on the numbers of nematode IJs entering the host. We assumed binomial error variance for mortality data and quasi-Poisson error variance for IJ numbers infecting, which in most cases were small integer data, using where possible empirically estimated scale parameters to account for potential overdispersion. After rescaling, the significance of explanatory variables was assessed by $F$ ratio tests and by the change in deviance when a variable was removed from the full model. The influence of sand content and compaction on sex ratio of invading IJs (proportion males) data were explored with logistic regression assuming quasi-binomially distributed errors to counter the effects of overdispersion (Wilson and Hardy, 2002). Since multiple culture batches for each EPN species were used, we also ran generalized linear mixed models with each culture batch fitted as a random variable to confirm the result of the initial analyses, but presented only if results are different. Further sub-analyses for each species were run separately to explore possible significant interactions between species and sand content and also between species and compaction. All analyses were performed in Genstat V14.1 (VSN International, Hemel Hempstead, UK).

\section{RESULTS}

\section{Mortality of Galleria larvae}

The mortality (= parasitism) of Galleria larvae was on average $53 \cdot 9,95 \cdot 3$ and $50 \cdot 1 \%$ for $S$. carpocapsae, $S$. feltiae and $H$. downesi, respectively. The mortality of Galleria larvae was influenced by EPN species $\left(F_{2,762}=92 \cdot 36, P<0 \cdot 001\right.$, Fig. $\left.1 \mathrm{~A}\right)$, was positively correlated with sand content $\left(F_{1,762}=66 \cdot 62\right.$, $P<0.001$, Fig. $1 \mathrm{~A}$ and B) but was adversely affected by compaction $\left(F_{1,762}=36 \cdot 94, P<0 \cdot 001\right.$, Fig. 1B). There were also significant interactions between species and compaction $\left(F_{2,762}=6 \cdot 87\right.$, $P=0.001)$ and between sand content and compaction $\left(F_{2,762}=5 \cdot 81, P=0 \cdot 016\right)$. For $S$. carpocapsae, both sand content $\left(F_{4,220}=7 \cdot 56, P<0 \cdot 05\right)$ and compaction were significant $\left(F_{1,220}=22.52, P<0 \cdot 001\right.$, Fig. 2). For $H$. downesi, sand content was significant $\left(F_{4,250}=6 \cdot 50, P<0 \cdot 001\right)$, whereas compaction was marginally not significant $\left(F_{1,250}=3.63, P=0.058\right.$, Fig. 2). Lastly for $S$. feltiae, where mortality was close to $100 \%$ across treatments, neither sand content $\left(F_{1,274}=0.62, \quad P=0.648, \quad\right.$ Fig. 2$)$ nor compaction was significant $\left(F_{1,274}=0.62, \quad P=\right.$ 0·107, Fig. 2).

\section{Number of Ifs infecting Galleria larvae}

The numbers of IJs infecting Galleria larvae were influenced by all factors introduced in the model; in addition, second-level interactions between main effects were significant (Table 2). In summary, higher sand content led to higher number of IJs infecting the Galleria larvae, whereas compaction led to fewer IJs infecting the Galleria larvae (Fig. 3). Galleria larvae infected by S. feltiae had a greater number of nematodes (up to 122) upon dissection than Galleria larvae infected by $S$. carpocapsae and $H$. downesi, where the maximum numbers were 22 and 10, respectively (Fig. 3). Sub-analysis 
Table 1. Bulk density $\left(\mathrm{g} / 100 \mathrm{~cm}^{3}\right)$ of peat-sand mixture in different treatments of sand content and compaction $^{\mathrm{a}}$

\begin{tabular}{|c|c|c|c|c|c|c|}
\hline \multirow[b]{2}{*}{ Sand $(\%)$} & \multicolumn{2}{|l|}{ Uncompacted } & \multicolumn{2}{|l|}{ Compacted } & \multirow[b]{2}{*}{$t^{\mathrm{b}}$} & \multirow[b]{2}{*}{$P$} \\
\hline & Average \pm s.E. & Range & Average \pm s.E. & Range & & \\
\hline 0 & $16 \cdot 49 \pm 0 \cdot 069 \mathrm{a}$ & $14 \cdot 24-17 \cdot 53$ & $23 \cdot 15 \pm 0 \cdot 102 a$ & $21 \cdot 23-24 \cdot 85$ & $53 \cdot 81$ & $<0 \cdot 001$ \\
\hline 25 & $25 \cdot 79 \pm 0 \cdot 138 b$ & $22 \cdot 41-29 \cdot 20$ & $37 \cdot 24 \pm 0 \cdot 183 b$ & $33 \cdot 48-41 \cdot 9$ & $49 \cdot 77$ & $<0 \cdot 001$ \\
\hline 50 & $34 \cdot 81 \pm 0 \cdot 200 c$ & $31 \cdot 76-40 \cdot 19$ & $48 \cdot 77 \pm 0 \cdot 243 c$ & $45 \cdot 45-54 \cdot 55$ & $44 \cdot 25$ & $<0 \cdot 001$ \\
\hline 75 & $42 \cdot 21 \pm 0 \cdot 2046 \mathrm{~d}$ & $37 \cdot 22-46 \cdot 28$ & $57 \cdot 62 \pm 0 \cdot 233 \mathrm{~d}$ & $52 \cdot 38-62 \cdot 58$ & $49 \cdot 60$ & $<0 \cdot 001$ \\
\hline 100 & $52 \cdot 99 \pm 0 \cdot 313 \mathrm{e}$ & $49 \cdot 01-59 \cdot 28$ & $65 \cdot 14 \pm 0 \cdot 1848 \mathrm{e}$ & $60 \cdot 76-69 \cdot 33$ & $33 \cdot 35$ & $<0 \cdot 001$ \\
\hline$F_{4,384}$ & $4896 \cdot 52$ & & $7186 \cdot 47$ & & & \\
\hline$P^{T, 50 T}$ & $<0 \cdot 001$ & & $<0.001$ & & & \\
\hline
\end{tabular}

${ }^{a}$ Different letters show significant differences within column (one-way analysis of variance followed by a post hoc TukeyKramer test, $\alpha=0 \cdot 05)$.

b One-tailed $t$-test (uncompacted < compacted), across rows.

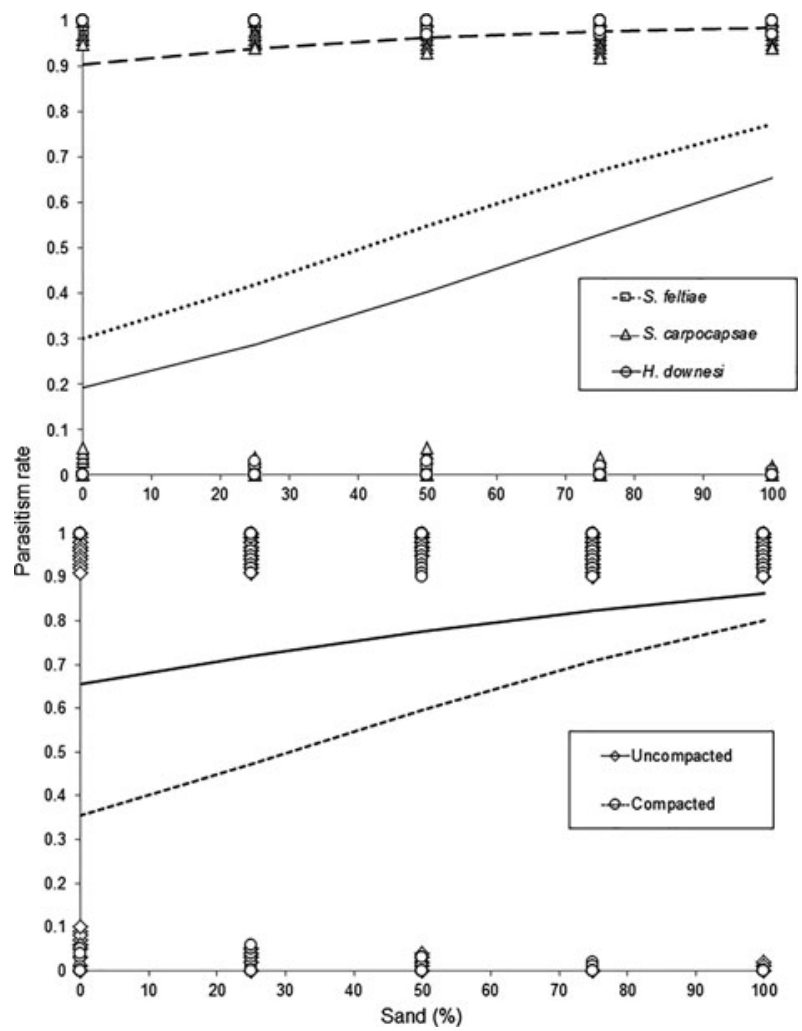

Fig. 1. The influence of sand content (A) and media compaction (B) on the parasitism rates of wax moth larvae caused by three species of entomopathogenic nematodes (logistic regression).

for each species separately revealed that in every case, sand content, compaction and their interaction were significant (data not shown).

\section{Medium and sex ratios in steinernematid nematodes}

Steinernema carpocapsae adult sex ratios upon cadaver dissection were not influenced by the number of individual adults $\left(F_{1,123}=0.56, P=\right.$ $0 \cdot 456)$ or compaction $\left(F_{1,123}=0 \cdot 39, P=0.533\right)$, but
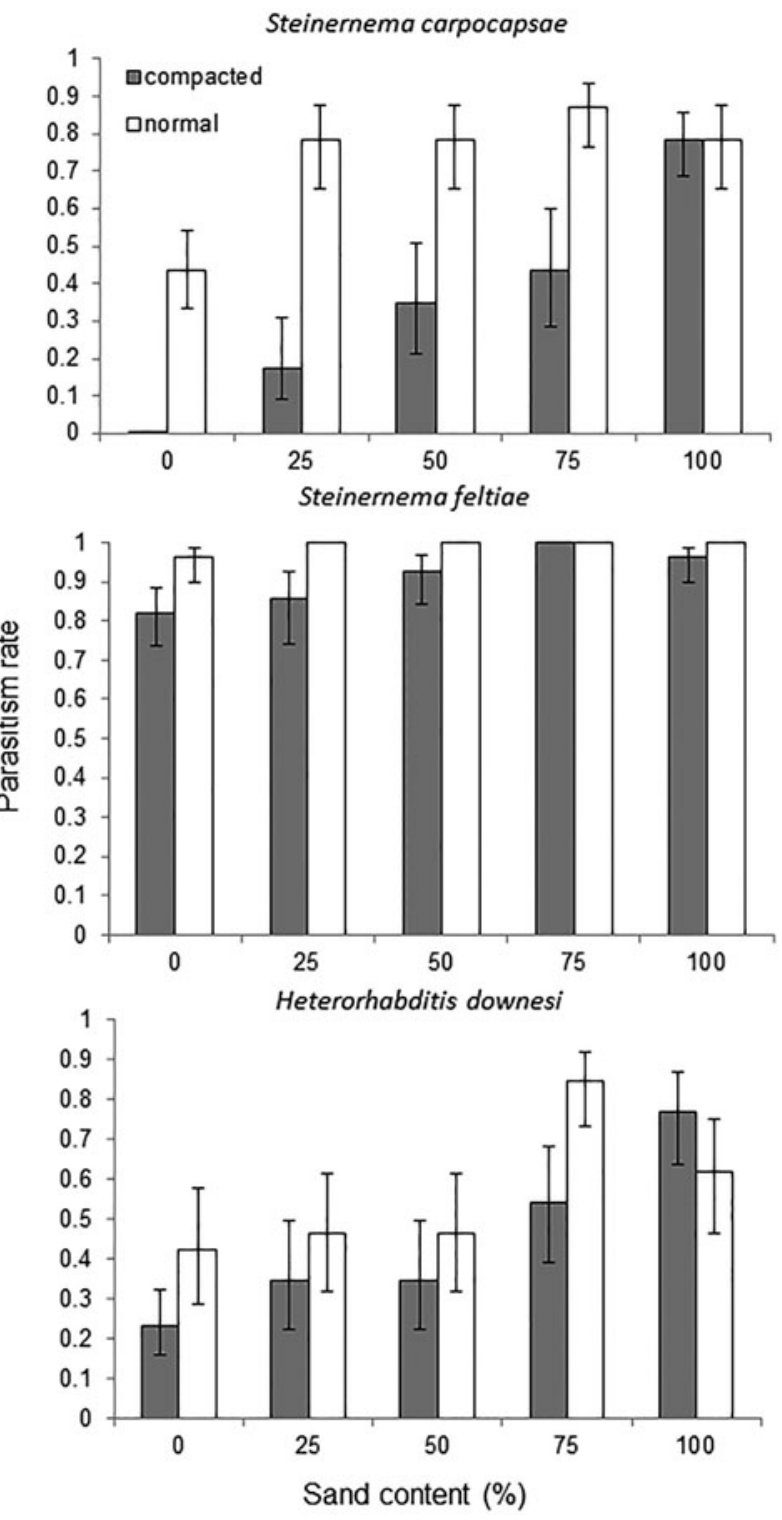

Fig. 2. Parasitism rates of wax moth larvae by Steinernema carpocapsae, Heterorhabditis downesi and Steinernema feltiae in media varying in peat:sand content and level of compaction. 
Table 2. Log-linear analysis of factors influencing the number of nematode IJs infecting Galleria larvae

\begin{tabular}{llrrr}
\hline \hline Effect & D.F. & Deviance & \multicolumn{1}{c}{$F$} & $P$ \\
\hline Nematode species & 2 & $9915 \cdot 772$ & $697 \cdot 71$ & $<0 \cdot 001$ \\
Sand & 1 & $2351 \cdot 493$ & $330 \cdot 92$ & $<0 \cdot 001$ \\
Compaction & 1 & $296 \cdot 133$ & $41 \cdot 67$ & $<0 \cdot 001$ \\
Nematode species $\times$ sand & 2 & $20 \cdot 345$ & $1 \cdot 43$ & $0 \cdot 240$ \\
Nematode species $\times$ compaction & 2 & $113 \cdot 981$ & $8 \cdot 02$ & $<0 \cdot 001$ \\
Sand $\times$ compaction & 1 & $240 \cdot 001$ & $33 \cdot 77$ & $<0 \cdot 001$ \\
Nematode species $\times$ sand $\times$ compaction & 2 & $15 \cdot 920$ & $1 \cdot 12$ & $0 \cdot 327$ \\
Residual & 758 & $5386 \cdot 332$ & & \\
Total & 769 & $18339 \cdot 977$ & & \\
\hline \hline
\end{tabular}
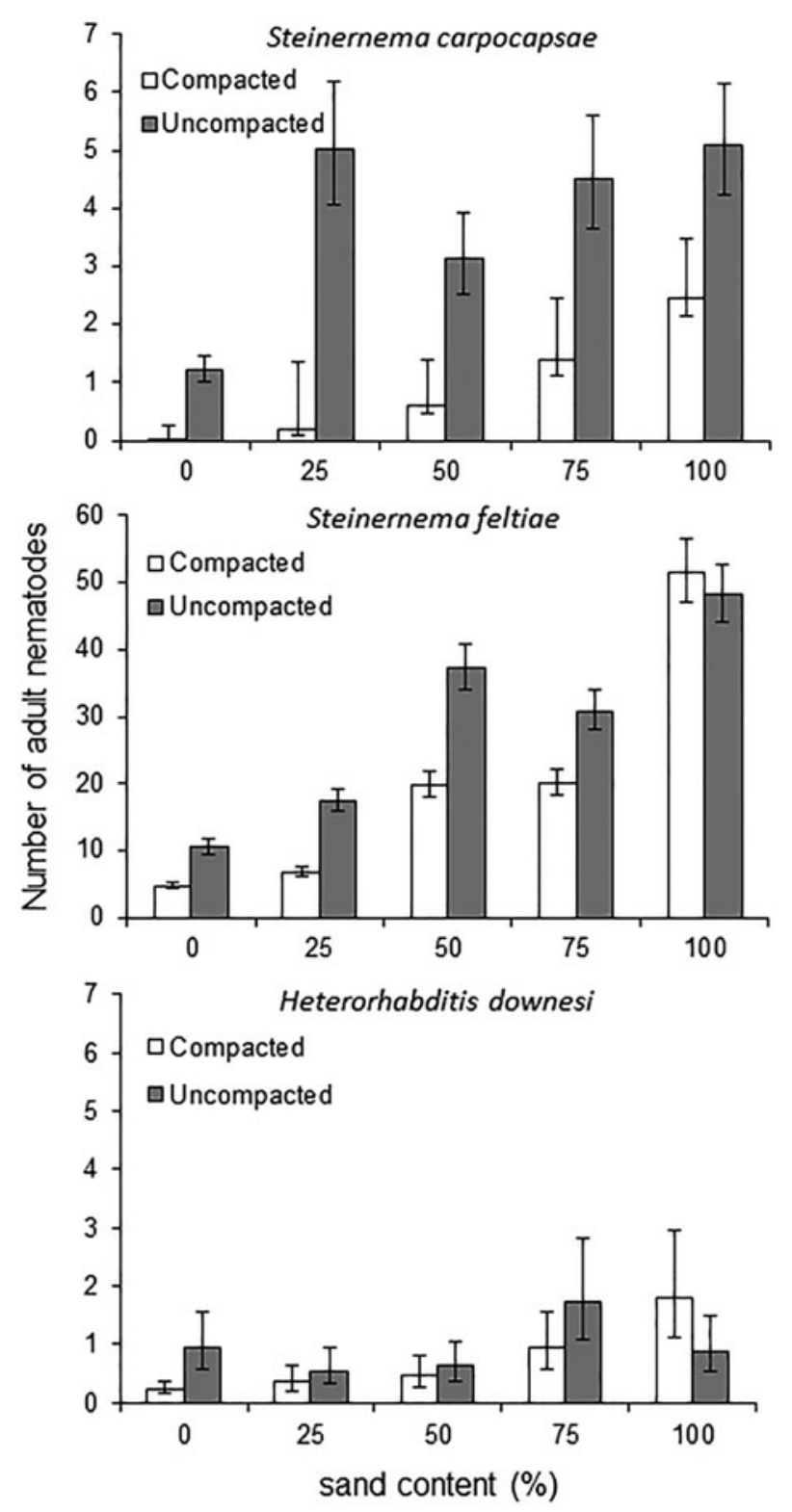

Fig. 3. Number of adult nematodes of Steinernema carpocapsae, Heterorhabditis downesi and Steinernema feltiae found upon dissection of wax moth larvae subjected to nematode infection in media varying in peat:sand content and level of compaction. sex ratios significantly decreased with increasing sand content $\left(F_{1,123}=4 \cdot 47, P=0 \cdot 037\right.$, Fig. 4$)$. Sex ratios of about $55.7 \%$ males in pure peat shifted to an average $39.4 \%$ males in pure sand as suggested by our regression model. Similarly, $S$. feltiae adult sex ratios were not influenced by the number of individual adults $\left(F_{1,259}=3.38, P=0.067\right)$ and were marginally decreased in compacted media $\left(F_{1,259}=\right.$ $3 \cdot 25, P=0 \cdot 072$, but a mixed model indicated that compaction was significant: $F_{1,259}=3 \cdot 99, \quad P=$ 0.047). Moreover, $S$. feltiae sex ratios significantly increased with increased sand content $\left(F_{1,259}=\right.$ $7 \cdot 08, P=0 \cdot 008$, Fig. 4). Thus, sex ratios ranged from $29 \cdot 7 \%$ males in pure peat to $35 \cdot 5 \%$ males in pure sand for compacted media, and from 31.5 to $38 \cdot 2 \%$ males (peat to sand) in uncompacted media.

\section{DISCUSSION}

Our experiments assessed the ability of three EPN species representing different foraging strategies to move through (and infect insects in) media with various peat:sand ratios and two levels of compaction, and showed that both factors had a marked influence, although these effects need to be addressed on an individual species level. A high sand content of soils generally facilitates nematode movement, though for the most part comparisons are done on soils with varying proportions of sand, silt and clay and rather low $(<5 \%)$ organic matter content (Georgis and Poinar, 1983; Kung et al. 1990; Portillo-Aguilar et al. 1999; Kaspi et al. 2010; El-Borai et al. 2012). In our study, increasing the sand content of the peat:sand mixture resulted in increasing numbers of nematodes finding and invading wax moth larvae for each of the three species tested: H. downesi (a cruise forager), S. carpocapsae (an ambusher) and S.feltiae, a species sharing properties of both foraging strategies (Campbell et al. 2003; Campos-Herrera and Gutiérrez, 2014). The trend was less evident for $S$. carpocapsae and $H$. downesi in uncompacted media. Similarly, physically altering various organic media with sand (up 


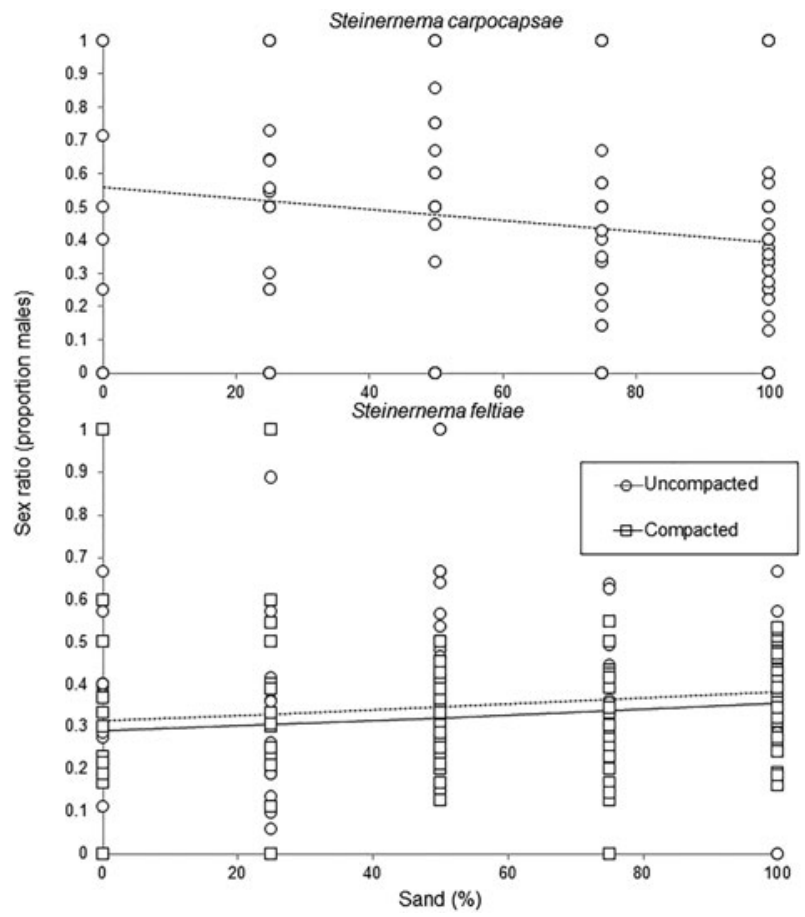

Fig. 4. The influence of peat:sand content and media compaction on sex ratios (proportion males) of Steinernema carpocapsae and Steinernema feltiae (logistic regression). Compaction is not significant for Steinernema carpocapsae and regression lines are presented only for the influence of sand content.

to $50 \%$ volume) improved foraging distance for $S$. riobrave, but not for $H$. bacteriophora (Nielsen and Lewis, 2011).

It is noteworthy that for $S$. carpocapsae, the lowest number of nematodes invading occurred in pure peat for both levels of compaction, much lower than in pure sand. This is in contrast to the findings of Kruitbos et al. (2010) who reported that $S$. carpocapsae did not display host finding in pure sand, but did in pure peat. It is notoriously difficult to compare across studies where details of assays, materials and nematode strains differ. For example, Kruitbos et al. (2010) measured relative proportions of nematodes moving towards or away from a host (and did not report absolute numbers of nematodes moving), while we measured numbers reaching (and invading) a host, where arrival at the host through the medium could have resulted either from host-specific orientation or random dispersal of the IJs. Thus, while it may be that orientation of $S$. carpocapsae towards a distant host is facilitated in peat, as shown by Kruitbos et al. (2010), our findings indicate that movement as measured by parameters more closely aligned with fitness (host death and nematode establishment) is impeded in pure peat relative to all other mixtures tested. Thus, our results do not support the hypothesis that $S$. carpocapsae is an organic habitat specialist. No mixture containing peat yielded a higher proportion of $S$. carpocapsae invading wax moths than pure sand, and in compacted media increasing the proportion of peat resulted in a steady decrease in invasion rate. While it is clear that $S$. carpocapsae can find and infect distant hosts, including in organic media (Lacey and Unruh, 1998; Dillon et al. 2006, 2007; Torr et al. 2005; Martinez de Altube et al. 2008; Dembilio et al. 2010; Santhi et al. 2015; Kapranas et al. $2017 a$ ), there is insufficient field data to indicate habitat specialization. An alternative hypothesis is that there are some IJs with enhanced dispersal ability relative to the average dispersal ability of the whole population and recent studies successfully selecting for better dispersing $S$. carpocapsae add some weight to this argument (Bal et al. 2014a,b; Santhi et al. 2016). A potential criticism of the experiment is that when peat and sand are mixed to create the different media, the moisture level may also change, and consequently the observed responses of our experiments may be influenced by differences in humidity as well as sand content. However, the moisture content in both pure sand and pure peat was optimal for nematode movement, and so it is unlikely that nematode movement was seriously impacted by sub-optimal moisture in any mixture. Therefore, the differences detected in the dispersal assays were due to the intended treatments (compaction, sand:peat ratios) rather than being an artefact of differing available moisture contents. A similar approach was employed also by Nielsen and Lewis (2011) who used dry sand to prepare a dilution series of organic media. While all three nematode species were negatively impacted by compaction of the medium, the extent to which they were affected differed between species. Soil compaction had a more adverse effect on $S$. carpocapsae than on the other two species, while $H$. downesi was the least affected. A similar differential response to increased bulk density (compaction) of mineral soils was reported by Portillo-Aguilar et al. (1999), with $S$. carpocapsae being more affected than either $H$. bacteriophora or $S$. glaseri (both of which are cruise foragers). For species such as S. carpocapsae that nictate (Campbell and Gaugler, 1993; Campbell and Kaya, 1999), lifting their body off the substrate can aid in bridging pores in soils and in organic media (Croll, 1970; Wilson et al. 2012) as well as being a strategy for attaching to passing hosts. Thus, compaction might have diminished their ability to move by bridging between particles within such media. Sand cannot be compacted as much as peat, so increasing sand content could improve properties of compacted soil. In the present study, the increase in sand ameliorated the negative effects of compaction, though $S$. carpocapsae was still negatively impacted by compaction of pure sand. 
It is evident that higher IJ invasion correlates with higher insect mortality in our experiments. Steinernema feltiae IJs were the most successful in invading and consequently killing most of the Galleria larvae in a broad range of media varying in peat content and compaction, even at the most adverse conditions of low sand content. For both $S$. carpocapsae and $H$. downesi, only a small proportion of IJs (typically $1-5$ of the 100 applied) infected Galleria hosts in media of any kind (\% peat-sand and compaction), compared with up to $50 \mathrm{IJs}$ in S. feltiae.

Examination of the sex ratios of the adult steinernematid nematodes within infected wax moths allows us to make inferences regarding the sex ratios of the infecting IJs. The composition of the medium affected the sex ratio of both species, but in opposite directions. As the proportion of sand increased, the proportion of males decreased for $S$. carpocapsae, and increased for S. feltiae. Alsaiyah et al. (2009) found that $S$. carpocapsae sex ratios in a similar sand assay did not differ from the sex ratio of nematodes developing in haemolymph (representing the underlying population sex ratio without influence of migration or responses to host). Thus, we can assume that in pure sand, male and female IJs of $S$. carpocapsae dispersed and invaded at similar rates (the sex ratio of invaders did not deviate from the population sex ratio of 0.43 as assessed in vitro). The results of the present study indicate that an increasing proportion of peat in the medium increasingly favours host finding and invasion by male $S$. carpocapsae, resulting in a deviation from the underlying population sex ratio, which becomes male-biased at higher peat contents. For S. feltiae, on the other hand, Alsaiyah et al. (2009) found that females in the population are more likely to invade than males (proportion males 0.35 in insects in sand assay compared with 0.43 in haemolymph). From the present study, there is evidence that this deviation from the population sex ratio of $S$. feltiae increases further in favour of females as the proportion of peat in the medium increases and under conditions of compaction. Similarly, Campos-Herrera and Gutiérrez (2014) found that the proportion of $S$. feltiae females in $G$. mellonella was higher in an assay requiring the IJs to migrate (conditions that restricted the number of nematodes entering the insects), than in a closecontact penetration assay. Previous studies on steinernematids suggest that differences between male and female IJs can have consequences for host colonization (Grewal et al. 1993; Bohan and Hominick, 1997; Alsaiyah et al. 2009). In our experiments, we show that in conditions hampering nematode movement (lower sand content and compacted medium), there are small but significant sex ratio shifts; this is direct evidence that there are sex-specific differences in dispersal of IJs, in a species-specific manner. Further research is warranted into the proximate mechanisms by which the physical structure of the medium affects sex ratio of $\mathrm{IJ}$ s finding and invading hosts, and the adaptive significance of the phenomenon.

In conclusion, both peat content and compaction influence nematode movement and efficacy. Our results suggest that nematodes, irrespective of their foraging strategy, move better through the soil matrix as the sand content increases, with the best performing species being S. feltiae, a species with intermediate foraging behaviour. We also show that the ratio of peat:sand can differentially influence the foraging behaviour of female and male $\mathrm{IJs}$ indicating that IJ infection patterns depend on interactions between their sex and physical properties of the medium in which they disperse.

\section{ACKNOWLEDGEMENTS}

We thank Sarajane Quinn for help in the laboratory.

\section{FINANCIAL SUPPORT}

This work was supported by the European Union Seventh Framework Programme (grant agreement number 612713 - BIOCOMES Project).

\section{REFERENCES}

Alsaiyah, M. A. M., Ebssa, L., Zenner, A., O'Callaghan, K. M. and Griffin, C. T. (2009). Sex ratios and sex-biased infection behavior in the entomopathogenic nematode genus Steinernema. International fournal of Parasitology 39, 725-734.

Ansari, M. A. and Butt, T. M. (2011). Effect of potting media on the efficacy and dispersal of entomopathogenic nematodes for the control of black vine weevil, Otiorhynchus sulcatus (Coleoptera: Curculionidae). Biological Control 58, 310-318.

Aritajat, U., Madge, D. S. and Gooderman, P. T. (1977). The effect of compaction of agricultural soils on soil fauna. I. Field investigations. Pedobiologia 17, 262-282.

Bal, H. K., Taylor, R. A. J. and Grewal, P.S. (2014a). Ambush foraging entomopathogenic nematodes employ 'sprinting emigrants' for long distance dispersal in the absence of hosts. Fournal of Parasitology 44, 450-451. Bal, H. K., Michel, A. P. and Grewal, P. S. $(2014 b)$. Genetic selection of the ambush foraging entomopathogenic nematode, Steinernema carpocapsae for enhanced dispersal and its associated trade-offs. Evolutionary Ecology 28, 923-939.

Beylich, A., Oberholzer, H., Schrader, S., Höper, H. and Wilke, B. (2010). Evaluation of soil compaction effects on soil biota and soil biological processes in soils. Soil Tillage Research 109, 133-143.

Bohan, D. A. and Hominick, W. M. (1997). Sex and the dynamics of infection in the entomopathogenic nematode Steinernema feltiae. Fournal of Helminthology 71, 197-201.

Bouwman, L. A. and Arts, W. B. M. (2000). Effects of soil compaction on the relationships between nematodes, grass production and soil physical properties. Applied Soil Ecology 14, 213-222.

Campbell, J. and Gaugler, R. (1993). Nictation behaviour and its ecological implications in the host search strategies of entomopathogenic nematodes (Heterorhabditidae and Steinernematidae). Behaviour 126, 154-169.

Campbell, J. F. and Kaya, H. K. (1999). How and why a parasitic nematode jumps. Nature 397, 485-486.

Campbell, J. F., Lewis, E. E., Stock, S. P., Nadler, S. and Kaya, H. K. (2003). Evolution of host search strategies in entomopathogenic nematodes. Fournal of Nematology 35, 142-145.

Campos-Herrera, R. and Gutiérrez, C. (2014). Steinernema feltiae intraspecific variability: infection process and sex-ratio. Fournal of Nematology 46, 35-43.

Choo, H. Y. and Kaya, H. K. (1991). Influence of soil texture and presence of roots on host finding by Heterorhabditis bacteriophora. Fournal of Invertebrate Pathology 58, 279-280. 
Cornelius, M. L. and Osbrink, W. L. A. (2010). Effect of soil type and moisture availability on the foraging behavior of the Formosan subterranean termite. Fournal of Economic Entomology 103, 799-807.

Croll, N. A. (1970). The Behavior of Nematodes: Their Activity, Senses and Responses. Edward Arnold, London.

Dembilio, O., Llacer, E., De Altube, M. M. and Jacas, J. A. (2010). Field efficacy of imidacloprid and Steinernema carpocapsae in a chitosan formulation against the red palm weevil Rhynchophorus ferrugineus (Coleoptera: Curculionidae) in Phoenix canariensis. Pest Management Science 66, 365-370.

Dillon, A. B., Ward, D., Downes, M. J. and Griffin, C. T. (2006). Suppression of the large pine weevil Hylobius abietis (L.) (Coleoptera: Curculionidae) in pine stumps by entomopathogenic nematodes with different foraging strategies. Biological Control 38, 217-226.

Dillon, A. B., Downes, M. J., Ward, D. and Griffin, C. T. (2007). Optimizing application of entomopathogenic nematodes to manage large pine weevil, Hylobius abietis L. (Coleoptera: Curculionidae) populations developing in pine stumps, Pinus sylvestris. Biological Control 40, 253-263. Eaton, R. J., Barbercheck, M., Buford, M. and Smith, W. (2004). Effects of organic matter removal, soil compaction, and vegetation control on Collembolan populations. Pedobiologia 48, 121-128.

El-Borai, F. E., Stuart, R. J., Campos-Herrera, R., Pathak, E. and Duncan, L.W. (2012). Entomopathogenic nematodes, root weevil larvae, and dynamic interactions among soil texture, plant growth, herbivory, and predation. Fournal of Invertebrate Pathology 109, 134-142. Georgis, R. and Poinar, G. O. (1983). Effect of soil texture on the distribution and infectivity of Neoaplectana carpocapasae (Nematoda: Steinernematidae). Fournal of Nematology 15, 308-311.

Grewal, P.S., Selvan, S., Lewis, E. E. and Gaugler, R. (1993). Male insect-parasitic nematodes: a colonizing sex. Experientia 49, 605-608. Grewal, P. S., Lewis, E. E., Gaugler, R. and Campbell, J. F. (1994). Host finding behaviour as a predictor of foraging strategy in entomopathogenic nematodes. Parasitology 108, 207-215.

Gruner, D. S., Ram, K. and Strong, D. R. (2007). Soil mediates the interaction of coexisting entomopathogenic nematodes with an insect host. Fournal of Invertebrate Pathology 94, 12-19.

Hunt, H. W., Wall, D. H., DeCrappeo, N. M. and Brenner, J. S. (2001) A model for nematode locomotion in soil. Nematology 3, 705-716.

Kaczmarek, W. (1978). Locomotory activity of soil fauna as a parameter of the trophic structure and of succession in forest ecosystems. Pedobiologia 18, 434-441.

Kapranas, A., Maher, A.M. D. and Griffin, C. T. (2016). Higher relatedness mitigates mortality in a nematode with lethal male fighting. Fournal of Evolutionary Biology 29, 344-351.

Kapranas, A., Malone, B., Quinn, S., McNamara, L., Williams, C. D., O' Tuama, P., Peters, A. and Griffin, C. T. (2017a). Efficacy of entomopathogenic nematodes for control of large pine weevil, Hylobius abietis: effects of soil type, pest density and spatial distribution. Fournal of Pest Science 90, 495-505.

Kapranas, A., Malone, B., Quinn, S., O'Tuama, P., Peters, A. and Griffin, C. T. $(2017 b)$. Optimizing the application method of entomopathogenic nematode suspension for Biological control of large pine weevil Hylobius abietis. Biocontrol. doi:10.1007/s10526-017-9824-x.

Kaspi, R., Ross, A., Hodson, A. K., Stevens, G. N., Kaya, H. K. and Lewis, E. E. (2010). Foraging efficacy of the entomopathogenic nematode Steinernema riobrave in different soil types from California citrus groves. Applied Soil Ecology 45, 243-253.

Kaya, H. K. and Gaugler, R. (1993). Entomopathogenic nematodes. Annual Review of Entomology 38, 181-206.

Kaya, H. K. and Stock, S. P. (1997). Techniques in insect nematology. In Manual of Techniques in Insect Pathology (ed. Lacey, L.), pp. 281-324. Academic Press, New York, USA.

Klingen, I. and Haukeland, S. (2006). The soil as a reservoir for natural enemies of pest insects and mites with emphasis on fungi and nematodes. In An Ecological and Societal Approach to Biological Control-Series: Progress in Biological Control, Vol. 2. (ed. Eilenberg, J. and Hokkanen, H. M. T.), pp. 145-211. Springer, Netherlands.

Koppenhöfer, A. M., Fuzy, E. M. (2006). Effect of soil type on infectivity and persistence of the EPNs Steinernema scarabaei, Steinernema glaseri, Heterorhabditis zealandica, and Heterorhabditis bacteriophora. Fournal of Invertebrate Pathology 92, 11-22.

Kruitbos, L. M., Heritage, S., Hapca, S. and Wilson, M. J. (2010). The influence of habitat quality on the foraging strategies of the entomopathogenic nematodes Steinernema carpocapsae and Heterorhabditis megidis. Parasitology 137, 303-309.

Kung, S.P., Gaugler, R. and Kaya, H. K. (1990). Soil type and entomopathogenic nematode persistence. Fournal of Invertebrate Pathology 55, 401-406. Lacey, L. A. and Unruh, T. R. (1998). Entomopathogenic nematodes for control of codling moth, Cydia pomonella (Lepidoptera: Tortricidae):
Effect of nematode species, concentration, temperature, and humidity. Biological Control 13, 190-197.

Lacey, L. A. and Georgis, R. (2012). Entomopathogenic nematodes for control of insect pests above and below ground with comments on commercial production. Fournal of Nematology 44, 218-225.

Lacey, L. A., Grzywacz, D., Shapiro-Ilan, D. I., Frutos, R., Brownbridge, M. and Goettel, M.S. (2015). Insect pathogens as biological control agents: back to the future. Fournal of Invertebrate Pathology 132, 1-41.

Lewis, E. E., Campbell, J., Griffin, C., Kaya, H. and Peters, A. (2006) Behavioral ecology of entomopathogenic nematodes. Biological Control 38, 66-79.

MacMillan, K., Haukeland, S., Rae, R., Young, I., Crawford, J., Hapca, S. and Wilson, M. (2009). Dispersal patterns and behaviour of the nematode Phasmarhabditis hermaphrodita in mineral soils and organic media. Soil Biology and Biochemistry 41, 1483-1490.

Martinez de Altube, M.D.M., Strauch, O., De Castro, G. F. and Pena, A. M. (2008). Control of the flat headed root borer Capnodis tenebrionis (Linné) (Coleoptera: Buprestidae) with the entomopathogenic nematode Steinernema carpocapsae (Weiser) (Nematoda: Steinernematidae) in a chitosan formulation in apricot orchards. BioControl 53, 531-539.

Mathieu, J., Barot, S., Blouin, M., Caro, G., Decaëns, T., Dubs, F., Dupont, L., Jouquet, P. and Nai, P. (2010). Habitat quality, conspecific density, and habitat pre-use affect the dispersal behaviour of two earthworm species, Aporrectodea icterica and Dendrobaena veneta, in a mesocosm experiment. Soil Biology and Biochemistry 42, 203-209.

Nielsen, A. L. and Lewis, E. E. (2011). Designing the ideal habitat for entomopathogen use in nursery production. Pest Management Science $\mathbf{6 8}$, 1053-1061.

O'Callaghan, K. M., Zenner, A. N. R. L., Hartley, C. J. and Griffin, C. T. (2014). Interference competition in entomopathogenic nematodes: male Steinernema kill members of their own and other species. International Fournal of Parasitology 44, 1009-1017.

O'Donnell, A. G., Young, I. M., Rushton, S. P., Shirley, M. D. and Crawford, J. W. (2007). Visualization, modelling and prediction in soil microbiology. Nature Reviews Microbiology 5, 689-699.

Oetting, R. D. and Latimer, J. G. (1991). An entomogenous nematode Steinernema carpocapsae is compatible with potting media environments created by horticultural practices. Fournal of Entomological Science 26, 390-394. Portillo-Aguilar, C., Villani, M. G., Tauber, M. J., Tauber, C. A. and Nyrop, J.P. (1999). Entomopathogenic nematode (Rhabditida: Heterorhabditidae and Steinernematidae) response to soil texture and bulk density. Environmental Entomology 28, 1021-1035.

Santhi, V.S., Salame, L., Nakache, Y., Koltai, H., Soroker, V. and Glazer, I. (2015). Attraction of entomopathogenic nematodes Steinernema carpocapsae and Heterorhabditis bacteriophora to the red palm weevil (Rhynchophorus ferrugineus). Biological Control 83, 75-81.

Santhi, V. S., Ment, D., Salame, L., Soroker, V. and Glazer, I. (2016). Genetic improvement of the attraction and host-seeking ability of the entomopathogenic nematodes Steinernema carpocapsae and Heterorhabditis bacteriophora to the Red Palm Weevil. Biological Control 100, 29-36.

Stuart, J. R., Barbercheck, M. E. and Grewal, P.S. (2015) Entomopathogenic nematodes in the soil environment: distributions, interactions and the influence of biotic and abiotic factors. In Nematode Pathogenesis of Insects and Other Pests - Ecology and Applied Technologies for Sustainable Plant and Crop Protection (ed. Campos-Herrera, R.), pp. 57-96. Springer International Publishing.

Torr, P. S., Wilson, M. J. and Heritage, S. (2005). Forestry applications. In Nematodes as Biocontrol Agents (ed. Grewal, P. S., Ehlers, R-U. and Shapiro-Ilan, D. I.), pp. 281-293. CABI Publishing, Oxfordshire.

Wallace, H. R. (1968). Dynamics of nematode movement. Annual Review of Phytopathology 6, 91-114.

Williams, C. D., Dillon, A. B., Girling, R. D. and Griffin, C. T. (2013) Organic soils promote the efficacy of entomopathogenic nematodes, with different foraging strategies, in the control of a major forest pest: a metaanalysis of field trial data. Biological Control 65, 357-364.

Wilson, K. and Hardy, I. C. W. (2002). Statistical analysis of sex ratios: an introduction. In Sex Ratios: Concepts and Research Methods (ed. Hardy, I. C. W.), pp. 48-92. Cambridge University Press, Cambridge, UK. Wilson, M. J., Ehlers, R.-U., Wilson, M. J. and Glazer, I. (2012). Entomopathogenic nematode foraging strategies - is Steinernema carpocapsae really an ambush forager? Nematology 14, 389-394.

Zenner, A. N. R. L., O'Callaghan, K. M. and Griffin, C. T. (2014). Lethal fighting in nematodes is dependent on developmental pathway: male-male fighting in the entomopathogenic nematode Steinernema longicaudum. PLoS ONE 9, e89385. 